Analisis Pengaruh Budaya Organisasi, Kualitas Pelayanan Dan Pola Komunikasi Terhadap Tingkat Loyalitas Nasabah Premier Wealth Pada PT Bank Maybank Indonesia Tbk Cabang Thamrin

(Meita Pragiwani; Mohammad Benny Alexandri; Siti Hadijah)

\title{
Analisis Pengaruh Budaya Organisasi, Kualitas Pelayanan Dan Pola Komunikasi Terhadap Tingkat Loyalitas Nasabah Premier Wealth Pada PT Bank Maybank Indonesia Tbk Cabang Thamrin
}

\author{
Meita Pragiwani ${ }^{1}$; Mohammad Benny Alexandri²; Siti Hadijah ${ }^{3}$ \\ ${ }^{1,3}$ Sekolah Tinggi Ilmu Ekonomi Indonesia; \\ ${ }^{2}$ Universitas Padjadjaran; \\ ola_168@yahoo.com; bennyalexandri@yahoo.co.id; siti.hadijah21@yahoo.com
}

\begin{abstract}
Abstrak
Hasil Penelitian yaitu variabel budaya organisasi, kualitas pelayanan dan pola komunikasi mempunyai berpengaruh positif dan signifikan terhadap tingkat loyalitas nasabah. Hal ini menunjukkan bahwa semakin baik budaya organisasi, kualitas pelayanan dan pola komunikasi PT. Bank Maybank Indonesia,Tbk Cab Thamrin, maka akan meningkatkan loyalitas nasabah premier wealth PT. Bank Maybank Indonesia,Tbk Cab Thamrin. Begitu pun sebaliknya, semakin buruk budaya oragnisasi, kualitas pelayanan dan pola komunikasi maka tidak akan meningkatkan loyalitas nasabah premier wealth PT. Bank Maybank Indonesia,Tbk Cab Thamrin. Hasil penelitian ini juga diharapkan dapat memberikan informasi bagaimana analisis budaya organisasi, kualitas pelayanan dan pola komunikasi terhadap tingkat pelayanan nasabah premier wealth yang masih kurang perlu di perbaiki dan yang sudah baik perlu ditingkatkan.
\end{abstract}

Kata Kunci : budaya organisasi, kualitas pelayanan, pola komunikasi dan loyalitas nasabah. 


\section{PENDAHULUAN}

Perbankan merupakan lembaga keuangan yang sangat penting peranan nya dalam kegiatan ekonomi, karena melalui kegiatan perkreditan dan berbagai jasa yang diberikan oleh bank maka dapat melayani berbagai kebutuhan pada berbagai sektor ekonomi dan perdagangan. Semakin maju nya globalisasi,dunia perbankan sangat berperan aktif bahkan dalam kemajuan perekonomian yang suplus (kelebihan dana) kepada unit perekonomian yang mengalami defisit (kekurangan dana). Sehingga dapat dikatakan bahwa bank merupakan inti dari sistem keuangan setiap negara.

Bank merupakan perusahaan keuangan yang bergerak dalam memberikan pelayanan keuangan yang mengandalkan kepercayaan dari masyarakat dalam mengelola dana nya (Kasmir, 2016 : 4). Para pelaku bisnis perkebunan, terutama dalam industri kelapa sawit dalam menghadapi tahun bisnisnya penuh dengan kehatian-hatian dan analisis yang sangat matang. Hal ini disebabkan beberapa tahun belakang terjadi resesi penurunan pertumbuhan ekonomi global terutama di Eropa dan Amerika yang berdampak pada Indonesia.

Memiliki nasabah yang loyal adalah harapan setiap manajemen bank, termasuk PT Bank Maybank Indonesia,Tbk hal ini karena loyalitas nasabah akan membuat bank mampu bertahan bahkan dapat meningkatkan keuntungan dari bank tersebut. Berbagai usaha dilakukan oleh pihak bank untuk menarik nasabah baru dan menjaga loyalitas dari nasabah yang sudah ada. Salah satu bentuk yang diberikan adalah melalui budaya organisasi,kualitas pelayanan dan menjaga komunikasi yang baik terhadap nasabah prioritas( premier wealth) . Nasabah prioritas ini walaupun jumlahnya sedikit namun jumlah dana mereka yang tersimpan di bank cukup besar. Sehingga nasabah prioritas tersebut diberi pelayanan khusus untuk memberikan nilai tambah dibandingkan dengan nasabah biasa(reguler) dan juga tingkat loyalitas nasabah terhadap bank tersebut terus dijaga agar nasabah prioritas ini tidak berpindah ke bank pesaing. Dalam memotivasi karyawan agar dapat meningkatkan kinerja tentu di support atau di dukung dengan pemberian kompensasi yaitu berupa gaji atau upah yang sepadan atas timbal balik hasil pencapaian yang dilakukan oleh para karyawan, ini terbukti dengan terdapatnya tren kenaikan biaya gaji yang dikeluarkan perusahaan selain dari faktor inflasi dan juga peraturan pemerintah. Dari besarnya kenaikan gaji ini tentu para manajer berharap dapat meningkatkan kinerja karyawan yang nantinya akan berpengaruh kepada produktivitas kerja perusahaan PT Bank Maybank Indonesia Tbk adalah salah satu bank swasta terkemuka di Indonesia yang merupakan bagian dari grup Malayan Banking Berhad (Maybank), salah satu grup penyedia layanan keuangan terbesar di ASEAN. Sebelumnya, Maybank Indonesia bernama PT Bank Internasional Indonesia Tbk (BII) yang didirikan pada 15 Mei 1959, mendapatkan ijin sebagai bank devisa pada 1988 dan mencatatkan sahamnya sebagai perusahaan terbuka di bursa efek Jakarta dan Surabaya (sekarang telah merger menjadi Bursa Efek Indonesia) pada 1989.

\section{Tujuan Penelitian}

Adapun tujuan dari penelitian ini adalah

1. Untuk mengetahui pengaruh budaya organisasi terhadap tingkat loyalitas nasabah premier wealth pada PT Bank Maybank Indonesia Tbk Cab Thamrin.

2. Untuk mengetahui pengaruh kualitas pelayanan terhadap tingkat loyalitas nasabah premier wealth pada PT Bank Maybank Indonesia Tbk Cab Thamrin. 
3. Untuk mengetahui pengaruh pola komunikasi terhadap tingkat loyalitas nasabah premier wealth pada PT Bank Maybank Indonesia Tbk Cab Thamrin.

4. Untuk mengetahui pengaruh budaya organisasi, kualitas pelayanan dan pola komunikasi terhadap tingkat loyalitas nasabah premier wealth pada PT Bank Maybank indonesia Tbk Cab Thamrin.

\section{TINJAUAN PUSTAKA}

\section{A. Budaya Organisasi}

Menurut pandangan Davis (2015):

"Budaya organisasi merupakan pola keyakinan dan nilai-nilai organisasional yang dipahami, dijiwai dan dipraktikkan oleh organisasional sehingga pola tersebut memberikan arti tersendiri dan menjadi dasar berperilaku dalam organisasional”.

Menurut pandangan Susanto (2016) : "Memberikan definisi budaya organisasi sebagai nilai-nilai yang menjadi pedoman sumber daya manusia untuk menghadapi permasalahan eksternal dan usaha penyesuaian integrasi kedalam perusahaan sehingga masing-masing anggota organisasi harus memahami nilai-nilai yang ada dan bagaimana mereka harus bertindak atau berperilaku.

\section{B. Kualitas Pelayanan Kualitas Pelayanan}

Kualitas pelayanan merupakan suatu fenomena yang unik, sebab dimensi dan indikatornya dapat berbeda diantara orangorang yang terlibat dalam pelayanan. Menurut Azwar untuk mengatasi perbedaan diatas seharusnya yang dipakai sebagai pedoman adalah hakikat dasar dari penyelenggaraan pelayanan kesehatan, yaitu memenuhi kebutuhan dan tuntutan para pemakai jasa pelayanan (Azwar, 2015). Kualitas pelayanan menunjuk pada tingkat kesempurnaan pelayanan dalam memenuhi kebutuhan dan tuntuan setiap konsumen. Azwar juga menjelaskan bahwa terpenuhi tidaknya kebutuhan dan tuntutan pemakai jasa pelayanan.

\section{Unsur-Unsur yang Mempengaruhi Kualitas Pelayanan}

Menurut Payne dimensi pelayanan jasa dapat terdiri atas unsur:

1) Tangible (bukti langsung) Dimana kemampuan perusahaan didalam menunjukan eksistensi dirinya, misalnya dalam hal ini gedung, fasilitas teknologi, penampilan karyawannya, an sebagainya lebih menekankan pada bukti secara fisik atau dapat diraba keberadaannya

2) Reliability (keandalan) Merupakan kemampuan perusahaan dalam memberikan pelayanan yang sesuai dengan yang dijanjikan kepada pelanggan. Hal ini dapat berupa adanya perbaikan kinerja yang sesuai dengan harapan pelanggan.

3) Responsiveness (daya tanggap) Daya tanggap yang dimiliki oleh karyawan dan pimpinan perusahaan. Dimana perusahaan harus menunjukkan kemampuannya dalam memberikan pelayanan yang cepat dan tepat kepada pelanggan jika pelanggan sedang memerlukan jasa yang dimaksudkan.

4) Emphaty (perhatian) Merupakan pemberian perhatian yang bersifat individu kepada pelanggan dari erusahaan. Hal ini dimaksudkan agar pihak perusahaan dapat memahami lebih auh tentang keinginan dan kebutuhan dari pelanggannya. (Nirwana,2016:29-30)

\section{Pola Komunikasi}


Komunikasi adalah suatu proses penyampaian informasi (pesan, ide, gagasan) dari satu pihak kepada pihak lain. Pada umumnya, komunikasi dilakukan secara lisan atau verbal yang dapat dimengerti oleh kedua belah pihak. apabila tidak ada bahasa verbal yang dapat dimengerti oleh keduanya, komunikasi masih dapat dilakukan dengan menggunakan gerak-gerik badan, menunjukkan sikap tertentu, misalnya tersenyum, menggelengkan kepala, mengangkat bahu. Cara seperti ini disebut komunikasi nonverbal.

Pola Komunikasi adalah proses pengiriman pesan dari satu pihak ke pihak lain melalui konteks tertentu seperti komunikasi intrapersonal, komunikasi antarpribadi atau interpersonal, komunikasi kelompok atau komunikasi organisasi, dan komunikasi massa. Ketika komunikasi berlangsung dalam konteks komunikasi kelompok atau komunikasi organisasi, maka akan memiliki jaringan komunikasi atau pola masing-masing

\section{Loyalitas Nasabah Loyalitas Nasabah}

Loyalitas nasabah merupakan perilaku yang terkait dengan merek sebuah produk, termasuk kemungkinkan memperbarui kontrak di masa yang akan datang, berapa kemungkinan nasabah mengubah dukungannya terhadap merek, berapa kemungkinan keinginan nasabah untuk meningkatkan citra positif suatu produk. Jika produk tidak mampu memuaskan nasabah, nasabah akan bereaksi dengan cara exit (nasabah menyatakan berhenti membeli merek atau produk) dan voice (nasabah menyatakan ketidakpuasan secara langsung pada perusahaan).

Faktor Yang Mempengaruhi Loyalitas Nasabah Faktor-faktor yang mempengaruhi loyalitas nasabah :

1. Tarif/Harga
2. Pelayanan

3. Promosi

4. Citra.

\section{Paradigma Penelitian}

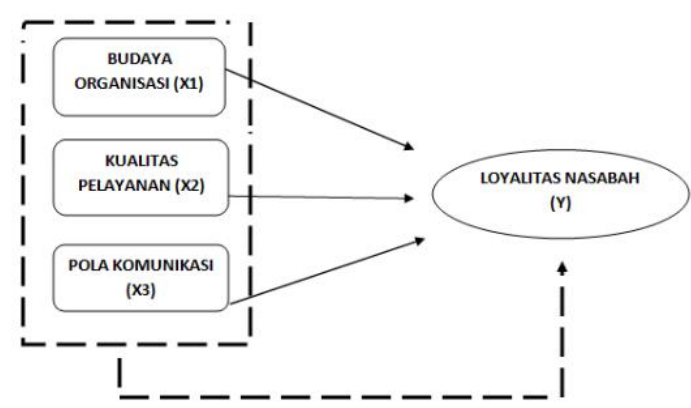

\section{Hipotesis}

H1: Terdapat Pengaruh Positif antara Budaya Organisasi terhadap Tingkat Loyalitas nasabah premier wealth pada PT Bank Maybank Indonesia, Tbk Cabang Thamrin

H2: Terdapat Pengaruh Positif antara Kualitas Pelayanan terhadap Tingkat Loyalitas nasabah premier wealth pada PT Bank Maybank Indonesia, Tbk Cabang Thamrin

H3: Terdapat Pengaruh Positif antara Pola Komunikasi terhadap Tingkat Loyalitas nasabah premier wealth pada PT Bank Maybank Indonesia, Tbk Cabang Thamrin.

H4: Terdapat Pengaruh Positif antara Budaya Organisasi, Kualitas Pelayanan dan Pola Komunikasi terhadap Tingkat Loyalitas nasabah premier wealth pada PT Bank Maybank Indonesia, Tbk Cabang Thamrin

\section{METEDOLOGI}

Penelitian ini dilakukan di PT Bank Maybank Indonesia Tbk Cabang Thamrin yang ber alamat di Jl MH Thamrin No.22 Kav. 51, Jakarta Pusat. Waktu yang ditempuh untuk penelitian ini dimulai dari 
penyusunan proposal penelitian sampai penyerahan versi akhir laporan penelitian diperkirakan selama 6(enam) bulan, terhitung dari bulan September 2018 sampai dengan Februari 2019.

Dalam instrumen pengumpulan data yang digunakan dalam penelitian ini adalah kuesioner, yang di ukur dengan skala Likert yang di gunakan untuk mengukur sikap, pendapat maupun persepsi seseorang. Kuesioner yang digunakan adalah kuesioner yang tertutup yang telah disediakan pilihan jawaban dalam hal ini berupa jawaban sangat setuju,setuju,raguragu,tidak setuju dan sangat tidak setuju. Pengolahan data dalam analisis ini menggunakan program software Statistical Product and Service Solution (SPSS) versi 23 umtuk analisi data. Sedangkan penyajian data nya dengan menggunakan tabel dan statistik.

Analisis Regresi Linear Berganda

$$
\hat{\mathrm{Y}}=\mathrm{b} 0+\mathrm{b} 1 \mathrm{x} 1+\mathrm{b} 2 \mathrm{x} 2+\mathrm{b} 3 \mathrm{x} 3+\dot{\varepsilon} \text { (Rumus }
$$

Persamaan Regresi 3.1)

Keterangan :

$$
\begin{aligned}
& \hat{\mathrm{Y}} \quad=\text { Loyalitas Nasabah } \\
& \text { X1 = Budaya Organisasi } \\
& \text { X2 }=\text { Kualitas Pelayanan } \\
& \text { X3 }=\text { Pola Komunikasi } \\
& b \quad=\text { Intercept }
\end{aligned}
$$

\section{Koefisien Determinasi (R2)}

Dalam penelitian ini, peneliti menggunakan R2 dengan tujuan untuk mengukur besarnya pengaruh variabel bebas $(\mathrm{X})$ terhadap variabel terikat $(\mathrm{Y})$. Koefisien determinasi pada dasarnya untuk mengukur seberapa jauh kemampuan model dalam menerangkan variasi variabel dependen

\section{DISKUSI DAN PEMBAHASAN}

Hasil dari data yang telah didapat dan diolah selama proses penelitian dijelaskan sebagai berikut;

1. Penentuan estimasi model data panel yang terbaik dalam penelitian ini adalah menggunakan model Random Effect Model (REM)

2. Data yang diperoleh dilakukan uji asumsi klasik sebagai syarat uji kelayakan data

3. Pengolahan data menggunakan software Econometric Views

Model penelitian ini adalah sebagai berikut :

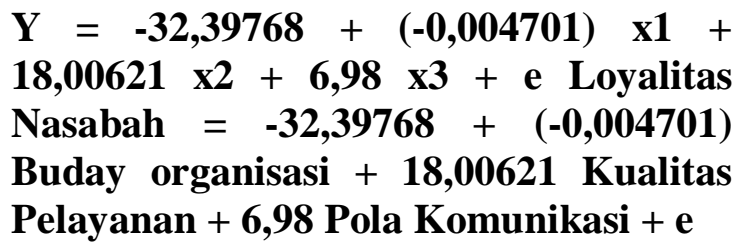

\section{Koefisien Determinasi}

Berdasarkan pembahasan di atas, menunjukkan bahwa R2

$=0,644$, hal ini berarti $64,4 \%$ variasi dari kinerja dapat dijelaskan oleh variasi dari ke tiga variabel independen yaitu budaya organisasi, kualitas pelayanan dan pola komunikasi, sedangkan sisa nya ( $100 \%$ $64,4 \%=35,6 \%$ ) dijelaskan oleh faktor lain yang tidak diteliti. .

\section{Uji t (parsial)}

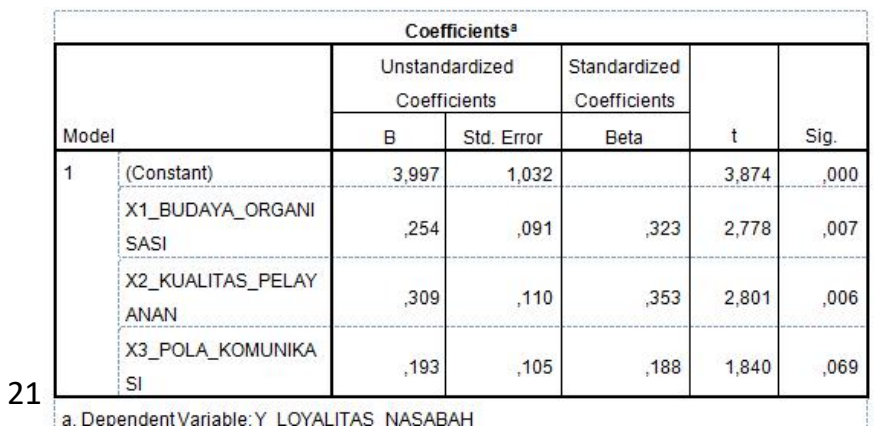


Adapun penjelasan terhadap masingmasing variabel adalah sebagai berikut :

a. Budaya Organisasi (X1) sebesar 0,007, lebih kecil dari taraf nyata yaitu 0,05. Dari hasil tersebut dapat ditarik kesimpulan bahwa H0 di tolak dan Ha diterima, maka secara parsial terdapat pengaruh yang positif antara variabel Budaya Organisasi ( X1 ) terhadap tingkat loyalitas nasabah (Y).

b. Kualitas Pelayanan (X2 ) sebesar 0,006, lebih kecil dari taraf nyata yaitu 0,05. Dari hasil tersebut dapat ditarik kesimpulan bahwa H0 di tolak dan Ha diterima, maka secara parsial terdapat pengaruh yang positif antara variabel Kualitas Pelayanan ( X2 ) terhadap tingkat loyalitas nasabah (Y).

c. Pola Komunikasi ( X3 ) sebesar 0,069, lebih kecil dari taraf nyata yaitu 0,05. Dari hasil tersebut dapat ditarik kesimpulan bahwa H0 di tolak dan Ha diterima, maka secara parsial terdapat pengaruh yang positif antara variabel Pola Komunikasi ( X3 ) terhadap tingkat loyalitas nasabah $(\mathrm{Y})$.

Dari hasil tersebut dapat ditarik kesimpulan bahwa $\mathrm{HO}$ di tolak dan $\mathrm{Ha}$ diterima, maka secara simultan terdapat pengaruh yang positif antara variabel Budaya Organisasi( X1), Kualitas Pelayanan (X2) dan Pola Komunikasi( X3 ) , terhadap tingkat Loyalitas Nasabah (Y), artinya secara bersama- sama variabel Budaya Organisasi( X1 ), Kualitas Pelayanan( X2 ) dan Pola Komunikasi (X3) mempunyai pengaruh terhadap tingkat Loyalitas Nasabah Premier Wealth pada PT Bank Maybank Indonesia,Tbk.

\section{KESIMPULAN DAN SARAN}

\section{Kesimpulan}

1.Variabel budaya organisasi berpengaruh positif dan signifikan terhadap tingkat loyalitas nasabah. Hal ini menunjukkan bahwa semakin baik budaya organisasi PT. Bank Maybank Indonesia,Tbk Cab Thamrin, maka akan meningkatkan loyalitas nasabah premier wealth PT. Bank Maybank Indonesia,Tbk Cab Thamrin.

2.Variabel kualitas pelayanan berpengaruh positif dan signifikan terhadap tingkat loyalitas nasabah. Hal ini menunjukkan bahwa semakin baik kualitas pelayanan PT. Bank Maybank Indonesia,Tbk Cab Thamrin, maka akan meningkatkan loyalitas nasabah premier wealth PT. Bank Maybank Indonesia,Tbk Cab Thamrin.

3.Variabel pola komunikasi berpengaruh positif dan signifikan terhadap tingkat loyalitas nasabah. Hal ini menunjukkan bahwa semakin baik pola komunikasi PT. Bank Maybank Indonesia,Tbk Cab Thamrin, maka akan meningkatkan loyalitas nasabah premier wealth PT. Bank Maybank Indonesia,Tbk Cab Thamrin. 4.Variabel budaya organisasi, kualitas pelayanan dan pola komunikasi mempunyai berpengaruh positif dan signifikan terhadap tingkat loyalitas nasabah. Hal ini menunjukkan bahwa semakin baik budaya organisasi, kualitas pelayanan dan pola komunikasi PT. Bank Maybank Indonesia,Tbk Cab Thamrin, maka akan meningkatkan loyalitas nasabah premier wealth PT. Bank Maybank Indonesia,Tbk Cab Thamrin. Begitu pun sebaliknya, semakin buruk budaya oragnisasi, kualitas pelayanan dan pola komunikasi maka tidak akan meningkatkan loyalitas nasabah premier wealth PT. Bank Maybank Indonesia,Tbk Cab Thamrin.

\section{Saran}


1. Dalam budaya organisasi masih perlu di lakukan sesuai standar yang tepat oleh karyawan demi menjaga tingkat loyalitas nasabah premier wealth PT. Bank Maybank Indonesia,Tbk Cab Thamrin.

2. Kualitas pelayanan harus konsisten di jalankan sesuai dengan flow atau alur dan SOP yang berlaku khususnya pelayanan untuk nasabah premier wealth PT. Bank Maybank Indonesia,Tbk Cab Thamrin.

3. Meminimalisir miss communication (kesalahan dalam komunikasi) antar karyawan sehingga memicu terjadi nya komplain nasabah yang berdampak pada pelayanan serta tingkat loyalitas nasabah.

4. Suasana kerja yang kondusif serta team work yang harus selalu dilaksanakan guna memberikan yang terbaik terhadap kebutuhan nasabah dan demi menjaga nama baik perusahaan.

\section{REFERENSI}

Ahmad Nasoha. 2016. Buku Ajar Ekonometrka. Yogyakarta : Deepublish

Barta Andrean Barus. New York: John wiley.

Dini, Muammar. 2016. Pengaruh Pelatihan Terhadap Produktivitas Kerja Karyawan. E-Journal Administrasi Bisnis Volume 4 nomor 1

Dias, Gary. 2015. Manajemen Sumber Daya Manusia. Jakarta: Salemba Empat.

Eko, Widodo Suparno. 2015. Manajemen Pengembangan Sumber Daya Manusia.
Yogyakarta : PUSTAKA PELAJAR.

Gaol. 2014. A to Z Human Capital (Manajemen Sumber Daya Manusia) Konsep, Teori, dan Pengembangan Dalam Konteks Organisasi Publik dan Bisnis, Jakarta : PT. Gramedia Widiasarana.

Gie, The Liang. 2009. Administrasi Perkantoran Modern. Yogyakarta : Liberty

Gomes. 2010. Manajemen Sumber Daya Manusia. Yogyakarta: Andi

Harry, T. Hani. 2012. Manajemen Personalia Dan Sumber Daya Manusia. Yogyakarta : BPFE

Hanief, Yulingga Nanda dan Wasis Himawanto. Statistik Pendidikan. Yogyakarta: CV Budi Utama. Hasibuan, Malayu. 2016. Manajemen Sumber Daya Manusia.Jakarta: PT Bumi Aksara

Hartono, Jogiyanto. 2011.Metodologi Penelitian Bisnis: Salah Kaprah dan Pengalaman-pengalaman. Yogyakarta : BPFE.

Komarudin. 2012. Manajemen Sumber Daya Manusia. Jakarta: STIA-LAN Press.

Kolil Jozef. 2010. Pengaruh Pelatihan Tenaga Kerja Dan Gaji Terhadap Produktivitas. Discussion Paper IZA No. 4731

Kusriyanto, Bambang. 2005. Meningkatkan Produktivitas Karyawan. Jakarta : PT.Gramedia Pustaka Utama

Mangkunegara. 2013. Manajemen Sumber Daya Manusia. Bandung : Remaja Rosdakarya

Mathis, R.L. \& J.H. Jackson. 2013. Human Resource Management: Manajemen Sumber Daya Manusia. Terjemahan Dian Angelia. Jakarta: Salemba Empat. 
Meager, Nigel. 2011. Upah Produktivitas

Dan pekerjaan : Tinjauan Teori Dan

Data Internasional. European

Employment Observatory Thematic

Expert ad-hoc Paper

Mulya, 2016. Sistem Informasi

Akuntansi. Jakarta: Salemba

Empat.

Nadia, Nasir. 2008. Analisa Pengaruh Tingkat Upah, Masa Kerja, Usia Terhadap Produktivitas Tenaga Kerja. Jurnal Ekonomi Pembangunan Universitas Brawijaya Malang

Ngurah, Gede. 2016 Pengaruh Modal

Dan Tenaga Kerja Terhadap Produksi Dan Pendapatan . EJurnal EP Unud, 8 [2]: 453-485

Notoatmodjo, S. 2010. Metodologi Penelitian Kesehatan. Jakarta : Rineka Cipta.

Nurjani dan Zulfikar Bagus Pambuko. 2018 Eviews untuk Analisis Ekonometrika Dasar: Aplikasi dan Interpretasi. Magelang: UNIMMA PRESS

Pandojo dan Suad. 2006.

Manajemen Personalia Edisi

Keempat Yogyakarta : BPFE UGM

Panjaitan, R. 2011. Manajemen Keperawatan: Manajemen Keperawatan di Ruang Rawat. Jakarta: Sagung Seto.

Poerwono 2013, Tata Personalia Edisi keIII, Jakarta : Djambatan

Rahardjo. 2009. Pengaruh Gaya Kepemimpinan Terhadap Kinerja Karyawan Sektor Perkebunan Surabaya. Jurnal Jurnal Akuntansi Bisnis Vol.1 No.1

Ria Chainar Elli. 2017. Pengaruh Pendidikan dan Latihan Tenaga Kerja Terhadap Peningkatan Produktifitas Kerja Karyawan. Jurnal Ekonomika dan Manajemen Vol. 6 No. 1
Rismayadi, Budi. 2015. Faktor-faktor Yang Mempengaruhi Produktivitas Karyawan. Jurnal Manajemen \& Bisnis Vol, 1 No, 1

Rinjani dan Samba. 2013. Manajemen Sumber Daya Manusia untuk Perusahaan. Jakarta : Rajawali Pers

\section{Romi, S, 2011 . Analisis Pengaruh Pelatihan Terhadap \\ Produktivitas Kerja Karyawan Pada PT. Erajaya Swasembada Cabang. Jurnal Ekonomika dan Manajemen Vol. 2No. 1}

Rumarini, Diah. 2010. Pengaruh Pengembangan Sumber Daya Manusia Terhadap Produktivitas Kerja Karyawan. Jurnal Ekonomi Modernisasi Fakultas EkonomiUniversitas Kanjuruhan Malang Vol 6,No 1

Santoso. 2018. Statistik Parametik. Jakarta : PT Gramedia Pustaka Umum.

Saprudin.2018. Pengaruh Pelatihan Dan Kompensasi Terhadap Produktivitas Kerja Karyawan. Journal on information system applied, management, accounting and research vol 2 no 2

Singh.2000. A Trestie on Phytochemistry. Emedia Sience Ltd. Simanjuntak, Payaman. 2012. Produktivitas Kerja Pengertian dan Ruang Lingkupnya, Prisma : Jakarta.

Sumarsono, S. 2009.Ekonomi Sumber Daya Manusia Teori dan Kebijakan Publik. Yogyakarta : Graha Ilmu.

Sinungan.2014. Produktivitas Apa dan Bagaimana. Jakarta : Bumi Aksara

Sugiyono. 2017. Metode Penelitian Kuantitatif Kualitatif dan R\&D. Bandung:Alfabeta.

Sutitris, Edwi. 2015. Manajemen Sumber Daya Manusia Edisi pertama. Jakarta: Kencana Prenada Media Group

Susilo Agus. 2003. Pengaruh Gaji, Kondisi kerja Dan Program Pelayanan Bagi 
Karyawan Terhadap Produktivitas Kerja. Jurnal Ekonomi dam Bismis Universitas Sebelas Maret Surakarta

Saila, Anwar. 2014. Pengaruh Pelatihan Kerja, Pengalaman Kerja dan Kompensasi Terhadap Produktivitas Kerja Karyawan. Jurnal Ekonomi dan Bisnis Universitas Dian Nuswantoro Semarang

Umar, Husein. 2004. Riset Sumber Daya Manusia Dalam Organisasi. Jakarta : Gramedia Pustaka Utama.
Uul Juni. 2016. Efek Manfaat Jumlah Karyawan Terhadap Produktivitas Karyawan.. The Journal of Applied Business ResearchSeptember/October 2016 Volume 32, Number 5 Korea Selatan

Winda, Agung. 2016. Pengaruh Pelatihan Dan Kompensasi Terhadap Produktivitas Karyawan. Journal Ekonomi - Manajemen Universitas Nusantara PGRI

Kediri Widzani. 2015. Pengaruh Pelatihan Tenaga Kerja Terhadap Produktivitas Karyawan. Jurnal Manajemen Universitas medan area 